\title{
Health-Seeking Behavior and Its Determinants among Mine Workers in the Karauli District of Rajasthan in India
}

\author{
Absar Ahmad \\ Faculty of Statistics, Department of Community Medicine, Career Institute of Medical Sciences and Hospital, \\ Lucknow, India
}

\section{Keywords}

Health facility · Utilization · Mine workers · India

\begin{abstract}
Background: Mine workers often need healthcare services in order to continue working without discomfort, making accessible and affordable healthcare a necessity. As the duration of working in mines is prolonged, there is a high chance of having an adverse effect on health. One of the important factors that influence the severity of disease among mine workers is their health-seeking behavior. The purpose of this paper is to assess the relationship between health-seeking behaviors by mine workers and their socio-demographic characteristics. Method: This is a quantitative, cross-sectional study conducted in the Karauli district of Rajasthan, India, during the period of May to September 2014. A total of 218 mine workers (exposed group) in 10 randomly selected villages were approached for participation. At the same time, a total of 203 eligible persons (a mix of occupational groups of people from the same villages) were also interviewed for comparison purposes. Data regarding the utilization of
\end{abstract}

healthcare services during the past 12 months along with socio-demographic information were recorded. Data were analyzed with $x^{2}$ and bivariate logistic regression statistical techniques. Results: Healthcare services were used by $73 \%$ of the workers in the past 12 months. With regard to working status, $80 \%$ of the mine workers and $66 \%$ of the non-mine workers availed themselves of healthcare services. Among the mine workers, the main reason for using healthcare services was respiratory illness (45\%); among the comparison group, it was infection (21\%). Logistics regression analysis found that the mine workers were more likely to require utilization of healthcare than the subjects in the comparison group were. The factors associated with utilization of healthcare services included the caste, BMI, and self-reported illness of the workers. Conclusion: Healthcare utilization patterns in the Karauli district revealed high utilization rates among mine workers over 12 months. Mainly respiratory illness was found to be the reason for healthcare utilization among mine workers. However, due to indifferent services they were frequently compelled to pay for private healthcare.

(C) 2019 The Author(s)

Published by S. Karger AG, Basel

\begin{tabular}{ll}
\hline KARGER & $\begin{array}{l}\text { K } 2019 \text { The Author(s) } \\
\text { Published by S. Karger AG, Basel }\end{array}$ \\
E-Mail karger@ker & Oparger.coms \\
www.karger.com/dmj & This article is licensed under the Creative Commons Attribution- \\
& $\begin{array}{l}\text { NonCommercial-NoDerivatives 4.0 International License (CC BY- } \\
\text { NC-ND) (http://www.karger.com/Services/OpenAccessLicense). } \\
\text { Usage and distribution for commercial purposes as well as any dis- } \\
\text { tribution of modified material requires written permission. }\end{array}$
\end{tabular}

Dr. Absar Ahmad

Faculty of Statistics, Department of Community Medicine

Career Institute of Medical Sciences and Hospital

IIM Road, Lucknow, Uttar Pradesh 226013 (India)

E-Mail r.absar.ahmad@gmail.com 


\section{Introduction}

Mining and quarrying are of vital economic importance to the state of Rajasthan in India, which produces $70 \%$ of the country's minerals [1]. More than $95 \%$ of the mining activity in Rajasthan is in the unorganized sector, and most of the workers are from disadvantaged social groups [1]. All of the people who work in mines have a high potential of exposure to various physical, chemical, mechanical, biological, and psychosocial risks [2] and thus a shorter life expectancy [3].

The occupational safety and health scenarios in India are complex, particularly for mine workers, while they cater to the needs of millions of workers in the informal economy [4]. A reason for poor occupational health could be that occupational health is not integrated into primary healthcare and it is always neglected among policymakers [5]. However, occupational health is well established as an integral part of health services in many industrialized nations [6]. Furthermore, on account of the medico-legal aspects of the cases, most of doctors hesitate to get involved in cases where worked-related health problems or hazards arise [7].

A study found that the average age of mine workers at the time of death was $51.8 \pm 12.5$ years [8]. One of the main reasons that a high mortality and a low life expectancy exist among mine workers in India is that working conditions are far from satisfactory, with mine administrators paying little heed to health and safety standards [9]. Workers are exposed to various types of biological, chemical, and physical agents, which can result in simple discomfort and irritation and, over an extended period, can lead to debilitating occupational diseases [10]. The problem of occupational disease like silicosis is much severe in sandstone mining in India since most of the mines are unorganized and do not fall under the purview of the statutory authorities and remedial measures [11]. As there is no specific therapy for silicosis, all steps have to be taken for its prevention only [11].

Mine workers are thus a vulnerable group [12] that requires better-organized healthcare services since their work environment is potentially dangerous [13] and they live in dire socioeconomic circumstances [14]. However, the utilization of healthcare services is influenced by social, individual, and systemic factors, as explained in a framework developed by Anderson [15]. The causes of this are: insufficient system resources; inappropriate allocation of resources across levels of care, programs, and regions; inadequate quality of services; insufficient household incomes; a lack of access to credit, and prohibitively expensive charges. This is aggravated by travel costs and cultural barriers to the acceptability of services, with misperceptions regarding illness and the effectiveness of care [16].

What makes this "quarryman's disease" in sandstone mines even more deadly is that none of the public health centers in the area is adequately equipped to intervene. As a result, patients are forced to consult expensive private doctors or incompetent quacks, pushing them into a vicious cycle of poverty and indebtedness [17]. Medical expenses are a significant factor in driving poor Indians deeper into poverty [18]. According to a study that used large-scale sample data, only $5 \%$ of households in India are covered by any health insurance. Among households belonging to the lowest economic categories, less than $3 \%$ are covered by any health scheme or health insurance [19].

The healthcare system in India in rural and urban areas is provided on 3 levels based on the population norms, ensuring access to primary care which is not affected by individual socioeconomic conditions [20]. However, many researchers have established the association between socioeconomic inequality and its adverse effects on health. A prevalence of poor health outcomes is observed among the scheduled castes (SC), women, and children as compared to other caste groups. Continuous health deprivation on the grounds of caste, race, and income poses challenges for the healthcare system in India [13] as well as abroad [21].

A 2004 study in rural Rajasthan found a lower utilization of public healthcare facilities correlated with declining health after controlling for age, gender, distance from a road, per capita monthly expenditures, poor health, and BMI [22].

Studies on the accessibility to healthcare services are common globally [23]. Despite a significant number of studies focusing on this in India as well, little attention has been paid to mine workers. Compared to non-mining households, mine workers have higher rates of poverty and sickness [24], and they are less likely to be covered by insurance or have a regular healthcare provider. However, no attempts have been made so far to study the utilization of health services among mine workers. With this background, we did a study to assess the treatment-seeking behavior of mine workers and examine their variations by socioeconomic and demographic factors in the Karauli district of Rajasthan in India.

\section{Materials and Methods}

A cross-sectional study of a comparison group of sandstone mine workers in the Karauli block of the Karauli district (Fig. 1) in Rajasthan was conducted during the period of May to September 2014 as part of a research program leading to the degree of $\mathrm{PhD}$. 
Fig. 1. Study area.

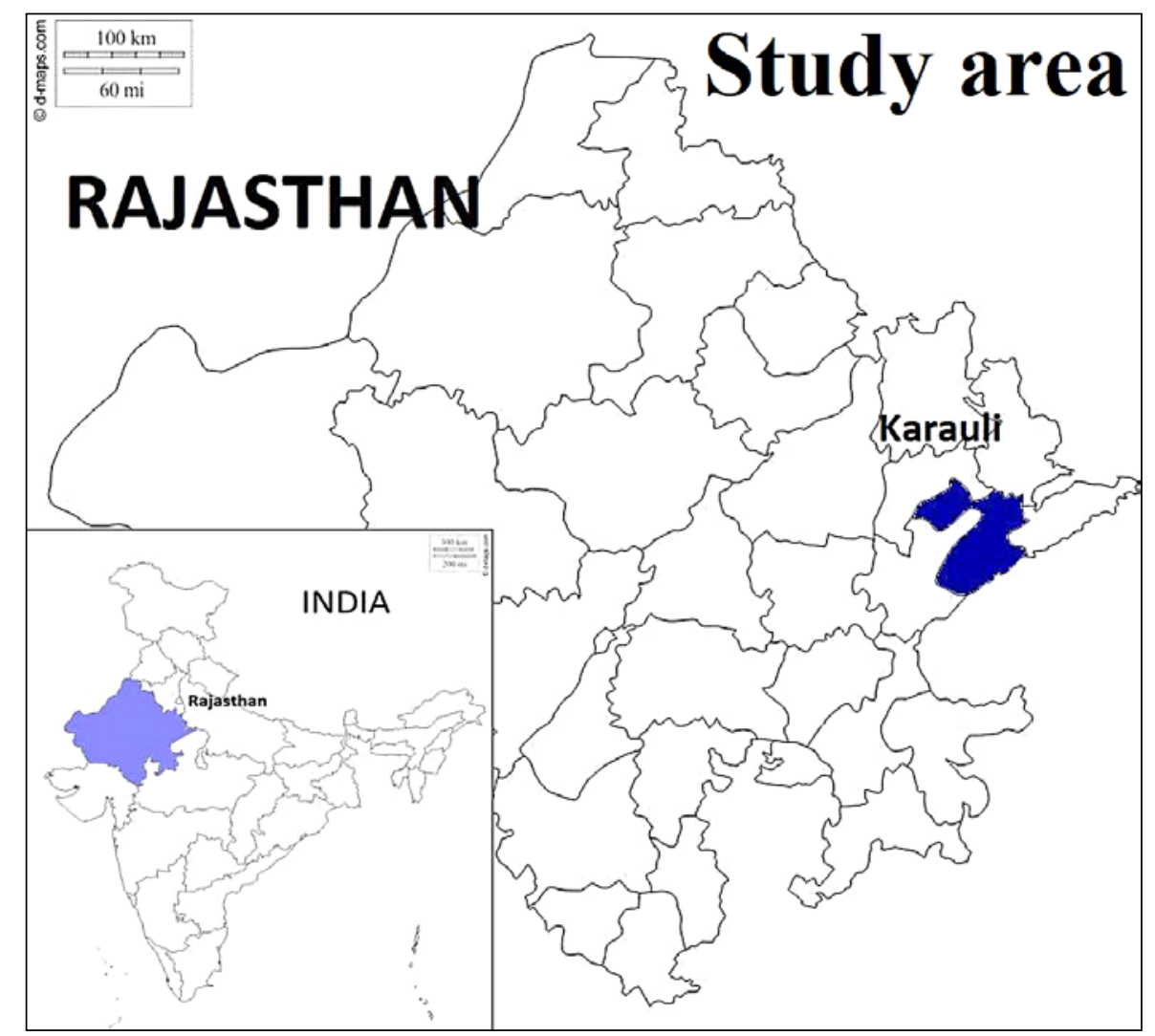

The Karauli block of the district Karauli of the state Rajasthan was selected for this study as a nongovernmental organization working for the betterment of mining and stone workers reported that $80 \%$ of the mining operation of the district Karauli is concentrated in the Karauli block.

The sample size for this study was determined using the following formula: $Z^{2} p q / d^{2}$ ( $p$ is the proportion of mine workers to the total workers in the Karauli block, $Z$ is the type 1 error at $5 \%$, and $d$ is the absolute error). Therefore, based on the sample size calculations ( $p=0.15, Z=1.96, d=0.05$ ), the requisite random and representative sample size was 196 mine workers. With the expectation of a $10 \%$ attrition rate [25], the final sample size was found to be 218 . The comparison group comprised 203 workers who had not worked in mines and lived in or close to the mine workers' residences and in similar socioeconomic conditions. They were farmers, daily-wage earners, drivers, small-shop owners, milkmen, washer men, carpenters, barbers, and salaried workers. These occupational groups were comparable to the mine workers in terms of most of the variables, except the risk of exposure to mining.

The two-stage sampling design was followed by an increase in the efficiency of the required number of respondents for interviews. In the first stage, 10 villages were selected using probability proportional to size sampling. In the second stage, the non-probability convenience sampling technique was used to select mine workers due to the lack of availability of a list of registered mine workers. A house-to-house inquiry was carried out in each selected village to approach mine workers and non-mine workers. The mine workers

Understanding Health-Seeking Behavior among Mine Workers
Table 1. Classification of reported illnesses

\begin{tabular}{ll}
\hline Illness category & Reported illness \\
\hline Respiratory illness & $\begin{array}{l}\text { Tuberculosis, silicosis, cough, cold, } \\
\text { shortness of breath, chest pain, asthma }\end{array}$ \\
\hline $\begin{array}{l}\text { Musculoskeletal } \\
\text { disorder }\end{array}$ & $\begin{array}{l}\text { Shoulder pain, lower back pain, joint pain, } \\
\text { knee pain }\end{array}$ \\
\hline Malaria & Malaria \\
\hline Injury & $\begin{array}{l}\text { Burn injury, injuries due to handling of } \\
\text { tools, attacked by an animal }\end{array}$ \\
\hline Infection & $\begin{array}{l}\text { Skin infection, cholera, jaundice, } \\
\text { periodontitis, short-duration fever }\end{array}$ \\
\hline Heat injury & Sunstroke \\
\hline Other & $\begin{array}{l}\text { Stomach pain, urine retention, vision loss, } \\
\text { hearing loss, gastritis, seizure, hypertension }\end{array}$ \\
\hline
\end{tabular}

and non-mine workers were selected at the discretion of the researcher and others were not involved in the selection process. This study included all workers over 15 years of age. The workers were generally cooperative, and no refusals were observed. 
The researcher himself stayed in villages to collect the data to minimize costs, save time, and experience the village life. Data were collected via face-to-face interviews using a pretested questionnaire with some open-ended questions to gain qualitative insights. The questionnaire covered the socio-demographic and occupational profiles of workers - i.e., gender, age, height, weight, marital status, religion, caste, income, educational level, and substance use. The questionnaire also asked for self-reported health information on occupational diseases. Further, the participants were asked: "Did you visit healthcare services during the past 12 months?" Twelve months was chosen because of the high rate of medical service utilization, and because it increased the chances of including those who rarely used healthcare services [26].

The reasons for using healthcare in the last 12 months and its categorization were determined with consultation of an MBBS doctor and are given in Table 1 .

Data were entered into Epi Info version 7, and SPSS 21 was used for statistical analysis. The characteristics of the study variables were summarized using descriptive statistics. To identify the factors associated with healthcare utilization among mine workers, bivariate and multivariate analyses were performed. Bivariate analyses were conducted to examine the nature of the association between the use of healthcare services by selected socioeconomic and demographic background characteristics. However, binary logistic regression was applied with a minimum confidence level of $p<0.05$ to investigate which factors best explain and predict the utilization of healthcare outcomes. Instead of the linear probability model, the logistic regression function is preferable to fit some kinds of sigmoid curves when the response variable is dichotomous, and that reasonably portrays the reality of outcome events. In the present study, the respondents were asked if they had used any health services as a result of any problem, discomfort, or illness in the last 12 months. The response was coded dichotomically, i.e., those who had used healthcare were coded as " 1 " and those who had not as "0."

Ethical approval was obtained from the Institutional Research Committee of the International Institute for Population Sciences, Mumbai, India. Verbal informed consent was obtained from each respondent before the data was collected. Anonymity and confidentiality were maintained, and no one was compelled to participate in this study.

\section{Results}

Data obtained were tabulated for analysis to achieve results. Table 2 provides the socioeconomic characteristics of the mine workers and the comparison group. About sixty percent of the mine workers were below 45 years of age, and the corresponding figure among comparison group was $69 \%$. Most of the mine workers were male $(98 \%)$ versus $82 \%$ of the comparison group. This study shows that $68 \%$ of the mine workers were either illiterate or had studied up to the primary level versus a corresponding figure of $55 \%$ for the comparison group. More than half of the mine workers belonged to the SC and were married (90\%), with the corresponding figures being 15 and $74 \%$ for the comparison group. The monthly household income of $50 \%$ of the mine workers was less than INR 4,000 as compared to a rate of $28 \%$ in the comparison group. About $19 \%$ of the mine workers and $14 \%$ of those in the comparison group reported an illness. More than $60 \%$ of the mine workers reported that the distance to the district hospital was more than $10 \mathrm{~km}$ as compared to $47 \%$ of the comparison group.

Table 3 shows the health-seeking behavior among mine workers and the comparison group. The utilization of healthcare among mine workers was higher among those aged less than 30 years (88\%), those with a primary education (91\%), SC (84\%), those with a reported illness (92\%), and those living near a district hospital (86\%). The corresponding rates for the comparison group were: 66 , $44,74,88$, and $64 \%$.

Table 4 provides details of healthcare service utilization by miners and the comparison group in the last 12 months, including inpatient and outpatient care. More than three fourths $(80 \%)$ of the mine workers and $66 \%$ of the comparison group used healthcare services in this period. The reasons were: respiratory illness (45\%), malaria (14\%), infection (14\%), and musculoskeletal disorders (12\%). More than half (54\%) of the mine workers sought treatment in a public healthcare facility, and about $2 \%$ also depended on traditional healers.

Table 5 describes the relationship between risk factors for healthcare utilization with adjustment for age, gender, education, marital status, caste, BMI, substance use, family size, family income, reported illness, distance from a district hospital, and mine work occupation. The logistic regression analysis shows that mine workers were more likely to require utilization of healthcare compared to the non-mine workers (AOR $=2.105 ; 95 \%$ CI 1.167-3.798). The independent risk factors for healthcare utilization among workers were seen among the "scheduled tribes" caste $(\mathrm{AOR}=0.362 ; 95 \%$ CI $0.149-0.88)$, those with a BMI of 25 or more (AOR $=0.277$; 95\% CI $0.105-0.73$ ), and those who reported an illness $(\mathrm{AOR}=4.107 ; 95 \% \mathrm{CI}$ 1.482-11.383).

\section{Discussion}

This study found that the utilization of healthcare services is considerably high among mine workers versus the comparison group in the Karauli district, and there was a wide variation by caste, marital status, BMI, and report of an illness. The disparity with the comparison group was 
Table 2. Basic characteristics of the mine workers and the comparison group

\begin{tabular}{|c|c|c|}
\hline & Mine workers & Comparison group \\
\hline \multicolumn{3}{|l|}{ Age, years } \\
\hline$<30$ & $43(19.70)$ & $61(30.00)$ \\
\hline $31-45$ & $98(45.00)$ & $80(39.40)$ \\
\hline $46-60$ & $71(32.60)$ & $34(16.70)$ \\
\hline $60+$ & $6(2.80)$ & $28(13.80)$ \\
\hline \multicolumn{3}{|l|}{ Gender } \\
\hline Male & $213(97.7)$ & $167(82.3)$ \\
\hline Female & $5(2.3)$ & $36(17.7)$ \\
\hline \multicolumn{3}{|l|}{ Educational level } \\
\hline Illiterate & $95(43.60)$ & $78(38.40)$ \\
\hline Primary & $53(24.30)$ & $34(16.70)$ \\
\hline High school or higher & $70(32.1)$ & $91(44.8)$ \\
\hline \multicolumn{3}{|l|}{ Marital status } \\
\hline Single & $12(5.5)$ & $31(15.3)$ \\
\hline Married & $198(90.8)$ & $151(74.4)$ \\
\hline Divorced/separated & $8(3.7)$ & $21(10.3)$ \\
\hline \multicolumn{3}{|l|}{ Caste } \\
\hline SC & $116(53.20)$ & $31(15.30)$ \\
\hline ST & $23(10.60)$ & $14(6.90)$ \\
\hline $\mathrm{OBC}$ & $73(33.50)$ & $126(62.10)$ \\
\hline General & $6(2.80)$ & $32(15.80)$ \\
\hline \multicolumn{3}{|l|}{ BMI } \\
\hline$<18.5$ & $83(38.10)$ & $72(35.50)$ \\
\hline $18.5-25$ & $130(59.60)$ & $111(54.70)$ \\
\hline 25 & $5(2.30)$ & $20(9.90)$ \\
\hline \multicolumn{3}{|l|}{ Substance use } \\
\hline Never & $23(10.60)$ & $55(27.10)$ \\
\hline Currently & $187(85.80)$ & $141(69.50)$ \\
\hline Ever & $8(3.70)$ & $7(3.40)$ \\
\hline \multicolumn{3}{|l|}{ Family size (members) } \\
\hline$<5$ & $86(39.40)$ & $109(53.70)$ \\
\hline$\geq 5$ & $132(60.60)$ & $94(46.30)$ \\
\hline \multicolumn{3}{|c|}{ Monthly family income (INR) } \\
\hline$<4,000$ & $113(51.8)$ & $57(28.1)$ \\
\hline $4,001-7,000$ & $66(30.3)$ & $57(28.1)$ \\
\hline 7,001 or higher & $39(17.9)$ & $89(43.8)$ \\
\hline \multicolumn{3}{|l|}{ Reported illness } \\
\hline No & $178(81.7)$ & $174(85.7)$ \\
\hline Yes & $40(18.3)$ & $29(14.3)$ \\
\hline \multicolumn{3}{|c|}{ Distance to a district hospital, $\mathrm{km}$} \\
\hline $0-10$ & $87(39.9)$ & $107(52.7)$ \\
\hline $10-20$ & $67(30.7)$ & $14(6.9)$ \\
\hline More than 20 & $64(29.4)$ & $82(40.4)$ \\
\hline Total & 218 & 203 \\
\hline
\end{tabular}

Values are presented as numbers (\%). Source: primary survey. ST, Scheduled tribes; OBC, other backward class.

substantial by age, gender, substance use, family income, and proximity to a district hospital.

In the last 12 months, more than three fourths of the mine workers $(80 \%)$ reported having visited a health fa- cility versus $66 \%$ of the comparison group. From this finding, it is evident that most mine workers suffer chronic health problems that have necessitated more hospital visits compared to the comparison group. The reason for 
Table 3. Study variables and bivariate analysis examining factors associated with health service utilization among mine workers and the comparison group

\begin{tabular}{|c|c|c|c|}
\hline & $\begin{array}{l}\text { Mine } \\
\text { workers }\end{array}$ & $\begin{array}{l}\text { Comparison } \\
\text { group }\end{array}$ & $\chi^{2}(p$ value $)$ \\
\hline \multicolumn{4}{|l|}{ Age, years } \\
\hline$<30$ & $38(88.4)$ & $40(65.6)$ & $26.43(0.000)$ \\
\hline $31-45$ & $78(79.6)$ & $51(63.8)$ & \\
\hline $46-60$ & $55(77.5)$ & $22(64.7)$ & \\
\hline $60+$ & $4(66.7)$ & $21(75.0)$ & \\
\hline \multicolumn{4}{|l|}{ Gender } \\
\hline Male & $170(79.8)$ & $104(62.3)$ & $28.82(0.000)$ \\
\hline Female & $5(100.0)$ & $30(83.3)$ & \\
\hline \multicolumn{4}{|l|}{ Educational level } \\
\hline Illiterate & $76(80.0)$ & $61(78.2)$ & $14.18(0.001)$ \\
\hline Primary & $48(90.6)$ & $15(44.1)$ & \\
\hline High school or higher & $51(72.9)$ & $58(63.7)$ & \\
\hline \multicolumn{4}{|c|}{ Marital status } \\
\hline Single & $8(66.7)$ & $20(64.5)$ & $17.15(0.000)$ \\
\hline Married & $159(80.3)$ & $98(64.9)$ & \\
\hline Divorced/separated & $8(100.0)$ & $16(76.2)$ & \\
\hline \multicolumn{4}{|l|}{ Caste } \\
\hline SC & $97(83.6)$ & $23(74.2)$ & $55.61(0.000)$ \\
\hline ST & $15(65.2)$ & $8(57.1)$ & \\
\hline OBC & $60(82.2)$ & $88(69.8)$ & \\
\hline General & $3(50.0)$ & $15(46.9)$ & \\
\hline \multicolumn{4}{|l|}{ BMI } \\
\hline$<18.5$ & $67(80.7)$ & $60(83.3)$ & $7.5(0.024)$ \\
\hline $18.5-25$ & $105(80.8)$ & $65(58.6)$ & \\
\hline 25 & $3(60.0)$ & $9(45.0)$ & \\
\hline \multicolumn{4}{|l|}{ Substance use } \\
\hline Never & $19(82.6)$ & $38(69.1)$ & $16.83(0.000)$ \\
\hline Currently & $150(80.2)$ & $89(63.1)$ & \\
\hline Ever & $6(75.0)$ & $7(100.0)$ & \\
\hline \multicolumn{4}{|l|}{ Family size (members) } \\
\hline$<5$ & $70(81.4)$ & $74(67.9)$ & $7.06(0.008)$ \\
\hline$\geq 5$ & $105(79.5)$ & $60(63.8)$ & \\
\hline \multicolumn{4}{|c|}{ Monthly family income (INR) } \\
\hline$<4,000$ & $94(83.2)$ & $39(68.4)$ & $26.83(0.000)$ \\
\hline $4,001-7,000$ & $48(72.7)$ & $36(63.2)$ & \\
\hline 7,001 or higher & $33(84.6)$ & $59(66.3)$ & \\
\hline \multicolumn{4}{|l|}{ Reported illness } \\
\hline No & $138(77.5)$ & $119(64.0)$ & $5.36(0.022)$ \\
\hline Yes & $37(92.5)$ & $15(88.2)$ & \\
\hline \multicolumn{4}{|c|}{ Distance to a district hospital, $\mathrm{km}$} \\
\hline $0-10$ & $75(86.2)$ & $68(63.6)$ & $27.57(0.000)$ \\
\hline $10-20$ & $53(79.1)$ & $9(64.3)$ & \\
\hline More than 20 & $47(73.4)$ & $57(69.5)$ & \\
\hline Total & $175(80.3)$ & $134(66.0)$ & \\
\hline
\end{tabular}

Values are presented as numbers (\%). Source: primary survey. ST, scheduled tribes; OBC, other backward class.
Table 4. Health care utilization in the 12 months preceding the survey

\begin{tabular}{lccl}
\hline & $\begin{array}{l}\text { Mine } \\
\text { workers }\end{array}$ & $\begin{array}{l}\text { Comparison } \\
\text { group }\end{array}$ & $\begin{array}{l}\chi^{2} \\
(p \text { value })\end{array}$ \\
\hline $\begin{array}{l}\text { Healthcare utilization } \\
\text { in the last year }\end{array}$ & & & \\
$\quad$ No & $43(19.7)$ & $69(34.0)$ & 10.95 \\
$\quad$ Yes & $175(80.3)$ & $134(66.0)$ & $(0.001)$ \\
If yes, for what reason & & & \\
$\quad$ Respiratory & $79(45.10)$ & $24(17.9)$ & 40.43 \\
$\quad$ Malaria & $24(13.70)$ & $16(11.90)$ & $(<0.001)$ \\
$\quad$ Musculoskeletal & & & \\
$\quad$ disorders & $21(12.00)$ & $14(10.4)$ & \\
Infection & $25(14.3)$ & $28(20.9)$ & \\
$\quad$ Heat injury & $6(3.40)$ & $6(4.5)$ & \\
$\quad$ Injury & $6(3.40)$ & $15(11.2)$ & \\
$\quad$ Other & $14(8.0)$ & $31(23.1)$ & \\
Type of health facility & $76(43.4)$ & $72(53.7)$ & 5.23 \\
$\quad$ Private & $95(54.3)$ & $56(41.8)$ & $(0.073)$ \\
$\quad \begin{array}{l}\text { Public } \\
\text { Traditional }\end{array}$ & $4(2.3)$ & $6(4.5)$ & \\
Satisfied with the service & & & \\
$\quad$ No & $26(14.9)$ & $22(16.4)$ & 0.15 \\
Yes & $149(85.1)$ & $112(83.6)$ & $(0.698)$ \\
\hline Total & 175 & 134 & \\
\hline
\end{tabular}

Values are presented as numbers (\%). Source: primary survey.

hospital visits among mine workers was mainly respiratory illness (45\%), while among the comparison group the primary reason was infection (21\%). Sandstone mine workers were more exposed to silica dust which causes silicosis [27], with symptoms like chronic cough, shortness of breath, chest pain, fever, fatigue, and weight loss. Patients with chronic silicosis could also present with associated conditions such as tuberculosis and lung cancer [28]. Some patients with simple silicosis could be asymptomatic and diagnosed incidentally after a radiological examination. Individuals might have a cough possibly because of nerve irritation caused by silicotic nodules or associated chronic obstructive pulmonary disease [28]. The clinical symptoms of silicosis and its progression are identical to those of tuberculosis [29], making it difficult to diagnose. A regular body screening is highly recommended for mine workers, but in reality it does not happened and this is largely the reason for most hospital visits. A complete recovery from silicosis is not possible and prescribed treatments give only some relief.

The present study reported $54 \%$ of the mine workers visited a public health facility and $43 \%$ visited a private 
Table 5. Binary logistic regression showing the adjusted effects of selected characteristics on utilization of healthcare services among workers in the Karauli district of Rajasthan

\begin{tabular}{|c|c|c|}
\hline Variable & Adjusted OR (95\% CI) & $p$ value \\
\hline \multicolumn{3}{|l|}{ Age, years } \\
\hline \multicolumn{3}{|l|}{$0-30^{\mathrm{a}}$} \\
\hline $31-45$ & $0.698(0.367-1.327)$ & 0.273 \\
\hline $46-60$ & $0.536(0.254-1.131)$ & 0.102 \\
\hline Over 60 & $0.743(0.264-2.087)$ & 0.573 \\
\hline \multicolumn{3}{|l|}{ Gender } \\
\hline \multicolumn{3}{|l|}{ Female $^{\mathrm{a}}$} \\
\hline Male & $2.958(0.931-9.396)$ & 0.066 \\
\hline \multicolumn{3}{|l|}{ Educational level } \\
\hline \multicolumn{3}{|l|}{ Illiterate $^{\mathrm{a}}$} \\
\hline Primary & $0.765(0.39-1.5)$ & 0.436 \\
\hline High school or higher & $0.798(0.436-1.461)$ & 0.465 \\
\hline \multicolumn{3}{|l|}{ Marital status } \\
\hline \multicolumn{3}{|l|}{ Single $\mathrm{a}^{\mathrm{a}}$} \\
\hline Married & $1.635(0.744-3.594)$ & 0.221 \\
\hline Divorced/separated & $1.855(0.436-7.895)$ & 0.403 \\
\hline \multicolumn{3}{|l|}{ Caste } \\
\hline \multicolumn{3}{|l|}{$\mathrm{SC}^{\mathrm{a}}$} \\
\hline ST & $0.362(0.149-0.88)^{\mathrm{b}}$ & 0.025 \\
\hline OBC & $1.004(0.515-1.956)$ & 0.991 \\
\hline General & $0.442(0.174-1.12)$ & 0.085 \\
\hline \multicolumn{3}{|l|}{ BMI } \\
\hline \multicolumn{3}{|l|}{$<18.5^{\mathrm{a}}$} \\
\hline $18.5-25$ & $0.614(0.358-1.052)$ & 0.076 \\
\hline Higher than 25 & $0.277(0.105-0.73)^{\mathrm{b}}$ & 0.009 \\
\hline \multicolumn{3}{|l|}{ Substance use } \\
\hline \multicolumn{3}{|l|}{ Never ${ }^{a}$} \\
\hline Currently & $0.965(0.504-1.849)$ & 0.915 \\
\hline Ever & $1.18(0.202-6.891)$ & 0.854 \\
\hline \multicolumn{3}{|l|}{ Family size (members) } \\
\hline \multicolumn{3}{|l|}{$<5^{\mathrm{a}}$} \\
\hline$>5$ & $0.958(0.568-1.615)$ & 0.872 \\
\hline \multicolumn{3}{|c|}{ Monthly family income (INR) } \\
\hline \multicolumn{3}{|l|}{$<4,000^{\mathrm{a}}$} \\
\hline $4,001-7,000$ & $0.765(0.423-1.381)$ & 0.373 \\
\hline 7,001 or more & $1.3(0.669-2.527)$ & 0.438 \\
\hline \multicolumn{3}{|l|}{ Reported illness } \\
\hline \multicolumn{3}{|l|}{$\mathrm{No}^{\mathrm{a}}$} \\
\hline Yes & $4.107(1.482-11.383)^{\mathrm{b}}$ & 0.007 \\
\hline \multicolumn{3}{|c|}{$\begin{array}{l}\text { Distance to a district hospital, } \mathrm{km} \\
\qquad 0-10^{\mathrm{a}}\end{array}$} \\
\hline $10-20$ & $1.438(0.623-3.321)$ & 0.394 \\
\hline More than 20 & $1.241(0.698-2.205)$ & 0.462 \\
\hline \multicolumn{3}{|l|}{ Mine worker } \\
\hline \multicolumn{3}{|l|}{$\mathrm{No}^{\mathrm{a}}$} \\
\hline Yes & $2.105(1.167-3.798)^{b}$ & 0.013 \\
\hline
\end{tabular}


health facility. These percentages among the comparison group were 42 and 54\%. Despite free healthcare facilities in the public health center, factors that influenced private hospital visits among mine workers who were not satisfied with their last visit to a public health facility included: noneffectiveness of treatment, nonavailability of essential drugs, and poor behavior of staff [30]. Another reason was mine workers being referred to a government hospital by a doctor at their private clinic for a checkup [30]. Also, mine workers went to "private practitioners," generally referred to as "compounders," for simpler health problems such as colds, coughs, fevers, and small cuts. These private practitioners are almost always male, practice in or close to their villages, and have attended school. Only $25 \%$ were graduates, and nearly $50 \%$ had no formal training. Regardless of this, nearly $90 \%$ of them practiced allopathy [31]. The mine workers did not undergo regular medical checkups [17], which are recommended.

Among the mine workers, of the $80 \%$ who reported having visited a health facility in the last 12 months, about $85 \%$ said they were satisfied with the services they received. The level of satisfaction with the healthcare received was dependent on the type of services sought and the availability of the services needed by the mine workers. Mostly mine workers got temporary relief thanks to medicine and started work again. Silicosis, a disease of mine workers, is incurable and when workers experience a new onset of symptoms they change either their doctor or their medication.

The present study did not find substance use to be statistically significantly correlated with healthcare utilization in the multivariate analysis. However, both were significant in the bivariate analysis. However, substance use is a public health concern in India [32] and it is directly associated with healthcare utilization, which may lead to injuries as well as respiratory illness and periodontitis that require medical attention, or may exacerbate physical illness [32]. One possible explanation for this relation could be that the use of substances did not differ between mine workers and the comparison group when controlling for background characteristics.

An earlier study found that the distance from a healthcare facility plays a significant role in choosing a healthcare utilization [33]. In the present study, this was also found to be significant in the bivariate analysis but not in multivariate analysis. Usually, when health worsens, distance is no longer a concern [33]. When residents decide to see a doctor for help, the travel time to the nearest clinic is not important [23], and some even travel to different cities [30]. Mine workers tend to seek treatment by taking a loan at a high interest rate from a contractor, which sometimes leads to mental stress among them [34].

Results from the logistic regression analyses indicated that those belonging to the scheduled tribes $(p<0.05)$ were less likely to use health services compare to SC when they felt unwell. Previous studies have demonstrated the role of discrimination in unequal access to healthcare; even public healthcare service providers discriminate the poor, SC, and scheduled tribes more than private healthcare providers do [35]. In the present study, most of the scheduled tribes were non-mine workers and involved in self-employed ventures and agriculture. So, workers of this caste are at a lower risk for the health hazards of mining compared those of other castes.

The BMI is used widely as a risk factor for the development of several health issues. The BMI has been useful in population-based studies by defining specific categories of body mass as a health problem [36]. Results from the logistic regression analyses indicated that those workers with a BMI over $25(p<0.05)$ were less likely to use health services than those with a BMI below 18.5. A low BMI among mine workers indicates silicosis or tuberculosis [8], which may lead to the use of healthcare services. Another reason may be that, due to their poor socioeconomic status, the diet quality of mine workers is reduced [30], which is associated with hospital visits [37]. It is also associated with symptoms such as feeling tired and getting sick often and an increased the risk of infection [38] that may lead to the utilization of healthcare services.

Workers with a reported illness $(p<0.05)$ were more likely to utilize health services. A 2014 study in Jordan also found that chronic illness was a predictor of healthcare utilization in the last 12 months [26]. Portraid et al. [39] reported that chronic morbidity is the most important determinant of the need for long-term care. Further, Ladwig et al. [40] described a positive relationship between self-reporting symptoms and overall utilization of health services, including frequency of medical visits, hospitalization in the preceding 12 months, and number and frequency of medications taken.

The logistic regression analysis also found that rate of healthcare service utilization by mine workers was higher than in the comparison group. The main reason for this is that they are more affected by health hazards as a result of poor working conditions as they do not use personal protective equipment [41]. A previous study in Karauli among mine workers showed a high prevalence of silicosis [9] as well as other morbidities [41]. The study also reported that morbidities among mine workers were significantly higher than among non-mine workers [41]. 
The reason for this could be a contribution by the category of workers who were manual or physical laborers, who were found to have a higher level of utilization of healthcare services [42].

This study has some limitations. First, the data were only from sandstone mine workers, so the results may not be representative of other minerals, mines, or regions. Further research is needed in other mining areas as well. Second, it used was self-reporting of health-related data, which could be biased. Indeed, workers could have misunderstood or not remembered every event covered by the survey. Also, information about socioeconomic and health status is not enough, and a study with a larger sample size might provide a different scenario regarding factors that influence healthcare utilization among workers, especially the female workers.

\section{Conclusion}

In the Karauli district, healthcare service utilization patterns reflected a high utilization rate among mine workers over 12 months. Mainly respiratory illness was found to be the reason for healthcare utilization among mine workers. However, mine workers often did not get proper health services at public facilities and were forced to opt for private healthcare. This study also identified a self-reported occupational illness to be the strongest predictor of healthcare service utilization.

\section{Acknowledgement}

The author expresses his gratitude to the subjects who agreed to participate in this study and gave their invaluable time. Also, the author extends his appreciation to the volunteers of the Dang Vikas Sansthan (Karauli), an NGO that provided help during field work.

\section{Statement of Ethics}

The author has no ethical conflicts to disclose.

\section{Disclosure Statement}

The author has no conflicts of interest to declare.

\section{Funding Sources}

No funding.

\section{References}

1 Sengupta R [Internet]. Report on ASM in Rajasthan. Available from: http://asmasiapacific.org/wp-content/uploads/2014/07/Rajasthan-Report-on-ASM.pdf.

2 Pule T. Mining activities and occupational health and safety at work. Afr Newsl Occup Health Saf. 2011;21(1):4-7.

3 Shen F, Yuan J, Sun Z, Hua Z, Qin T, Yao S, et al. Risk identification and prediction of coal workers' pneumoconiosis in Kailuan Colliery Group in China: a historical cohort study. PLoS One. 2013 Dec;8(12):e82181.

4 Rajesh R [Internet]. Occupational health services in India: challenges and opportunities [cited 2019 Feb 28]. Available from: http:// oem.bmj.com/.

5 Pingle SR [Internet]. Do occupational health services really exist in India? Available from: http://www.ttl.fi/en/publications/Electronic publications/Challenges_to_occupational_ health_services/Documents/India.pdf.

6 Gunatilake S, De Fonseka TEJ, Fernando DN. Integrating occupational health services with primary health care. Möbius. 1985;5(3):33-6.
7 PRIA [Internet]. Occupational Health in India. Available from: https://pria.org/uploaded_ files/article_category/Occupational_Health_ in_India_-_Making_a_Difference.pdf.

8 Mathur ML. Pattern and predictors of mortality in sandstone quarry workers quarry. In dian J Occup Environ Med. 2005;9(2):1-6.

9 National Institute of Miners' Health [Internet]. Detection Of silicosis among stone mine workers from Karauli district. Available from: http://aravali.org.in/themes/upload/ files/276725.pdf.

10 Donoghue AM. Occupational health hazards in mining: an overview. Occup Med (Lond). 2004 Aug;54(5):283-9.

11 Kulkarni GK. Prevention and control of silicosis: A national challenge. Indian J Occup Environ Med. 2007 Sep;11(3):95-6.

12 Aday L. At Risk in America: The Health and Health Care Needs of Vulnerable Populations in the United States. 2nd ed. San Francisco: Wiley; 2001.
13 Jungari S, Chauhan BG. Caste, Wealth and regional inequalities in health status of women and children in India. Contemp Voice Dalit. 2017 Apr;9(1):87-100.

14 Mathur B [Internet]. A study on the status of mining and mine workers in Rajasthan. Available from: https://www.barcjaipur.org/ download.php?fl=catImg_1447674685.pdf.

15 Anderson JG. Health services utilization: framework and review. Health Serv Res. 1973; 8(3):184-99.

16 O'Donnell O. Access to health care in developing countries: breaking down demand side barriers. Cad Saude Publica. 2007 Dec;23(12): 2820-34.

17 Center for Education and Communication [Internet]. Big profits, cheap lives: preliminary report of fact-finding study on working conditions in the sand stone mines in KotaBundi region of Rajasthan. Available from: www.cec-india.org.

18 Balarajan Y, Selvaraj S, Subramanian SV. Health care and equity in India. Lancet. 2011 Feb;377(9764):505-15. 
19 Shijith VP, Sekher TV. Who Gets Health Insurance Coverage in India?: New Findings From Nation-Wide Surveys. In: IUSSP International Population Conference. Busan, Republic of Korea; 2013. p. 1-26.

20 Chokshi M, Patil B, Khanna R, Neogi SB, Sharma J, Paul VK, et al. Health systems in India. J Perinatol. 2016 Dec;36(S3 s3):S9-12.

21 Hausmann LR, Jeong K, Bost JE, Ibrahim SA. Perceived discrimination in health care and health status in a racially diverse sample. Med Care. 2008 Sep;46(9):905-14.

22 Banerjee A, Deaton A, Duflo E. Health care delivery in rural Rajasthan. Econ Polit Wkly. 2004;39(9):944-9.

23 Fang P, Han S, Zhao L, Fang Z, Zhang Y, Zou $\mathrm{X}$. What limits the utilization of health services among the rural population in the Dabie Mountains- evidence from Hubei province, China? BMC Health Serv Res. 2014 Sep;14(1): 379.

24 Siddiqui Z, Lahiri-dutt K. Livelihoods of marginal mining and quarrying households in India. Econ Polit Wkly. 2015;L(26-27):27-32.

25 Whitley E, Ball J. Statistics review 4: sample size calculations. Crit Care. 2002 Aug;6(4): $335-41$.

26 Alkhawaldeh A, Holm MB, Qaddumi J, Petro W, Jaghbir M, Al Omari O. A Cross-sectional study to examine factors associated with primary health care service utilization among older adults in the Irbid governorate of Jordan. Curr Gerontol Geriatr Res. 2014;2014:735235.
27 Sutherland CL, Bryson S. Silicosis among sandstone workers. Lancet. 1929:297.

28 Leung CC, Yu IT, Chen W. Silicosis. Lancet. 2012 May;379(9830):2008-18.

29 Sharma DC. Miners fight for breath in Indian state. Lancet Respir Med. 2015 Mar;3(3):181.

$30 \mathrm{Ahmad}$ A. Are sandstone miners abused in India? Indian J Community Health. 2015; 27(2):286-9.

31 Rohde J, Viswanathan $\mathrm{H}$. The rural private practitioner. Health Millions. 1994 Feb;2(1): 13-6.

32 Dhawan A, Chopra A, Ray R. Preferences for treatment setting by substance users in India. Indian J Psychol Med. 2016 Jan-Feb;38(1): $42-5$.

33 Qian D, Pong RW, Yin A, Nagarajan KV, Meng Q. Determinants of health care demand in poor, rural China: the case of Gansu Province. Health Policy Plan. 2009 Sep;24(5):32434.

34 Ahmad A. Prevalence and predictors of occupational stress among quarry workers in rural Rajasthan, India. J Public Ment Health. 2017 Nov; 16(4):132-43.

35 Selvaraj S, Karan AK. Deepening health insecurity in India: evidence from national sample surveys since 1980s. Econ Polit Wkly. 2009;44(40):55-60.
36 Nuttall FQ. Body Mass Index: Obesity, BMI, and Health: A Critical Review. Nutr Today. 2015 May;50(3):117-28.

37 Ford DW, Hartman TJ, Still C, Wood C Mitchell DC, Bailey R, et al. Diet quality and body mass index are associated with health care resource use in rural older adults. J Acad Nutr Diet. 2014/04/18. 2014 Dec;114(12): 1932-8.

38 Dobner J, Kaser S. Body mass index and the risk of infection - from underweight to obesity. Clin Microbiol Infect. 2018 Jan;24(1): 24-8.

39 Portrait F, Lindeboom M, Deeg D. The use of long-term care services by the Dutch elderly. Health Econ. 2000 Sep;9(6):513-31.

40 Ladwig KH, Marten-Mittag B, Formanek B, Dammann G. Gender differences of symptom reporting and medical health care utilization in the German population. Eur J Epidemiol. 2000 Jun;16(6):511-8.

41 Ahmad A. Health risks among the sandstone quarry workers in rural Rajasthan: A crosssectional study. In: 35th Annual Conference of Indian Society for Medical Statistics. Lucknow; 2017.

$42 \mathrm{Kim} \mathrm{JH}$, Lee KS, Lee Y, Park EC. Association of Occupational Class with Healthcare Utilization among Economically Active Korean Adults from 2006 to 2014: A Repeated CrossSectional Study of Koreans Aged 19 Years and Older. Korean J Fam Med. 2017 Nov;38(6): 365-71. 